\title{
Immature platelets in patients hospitalized with Covid-19
}

\author{
Amir Cohen ${ }^{1} \cdot$ Emanuel Harari $^{1} \cdot$ Michal Cipok $^{2} \cdot$ Avishag Laish-Farkash $^{1} \cdot$ Gabriel Bryk $^{2}$ - Ella Yahud ${ }^{1} \cdot$ Yaron Sela $^{3}$. \\ Nili Karp Lador ${ }^{4} \cdot$ Tal Mann $^{4} \cdot$ Ami Mayo $^{4} \cdot$ Eli I. Lev $^{1}$ (1)
}

Accepted: 21 September 2020 / Published online: 30 September 2020

(c) Springer Science+Business Media, LLC, part of Springer Nature 2020

\begin{abstract}
Coronavirus disease 2019 (Covid-19) is associated with high incidence of venous and arterial thromboembolic events. Currently, there are no markers to guide antithrombotic therapy in Covid-19. Immature platelets represent a population of hyper-reactive platelets associated with arterial events. This prospective study compared consecutive Covid-19 patients (n $=47$, median age $=56$ years) to patients with acute myocardial infarction (AMI, $\mathrm{n}=100$, median age $=59$ years) and a group of stable patients with cardiovascular risk factors $(n=64$, median age $=68$ years). Immature platelet fraction (IPF) and immature platelet count (IPC) were determined by the Sysmex XN-3000 auto-analyzer on admission and at subsequent time-points. IPF\% on admission was higher in Covid-19 than the stable group and similar to the AMI group (4.8\% [IQR 3.4-6.9], 3.5\% [2.7-5.1], 4.55\% [3.0-6.75], respectively, $\mathrm{p}=0.0053$ ). IPC on admission was also higher in Covid-19 than the stable group and similar to the AMI group $\left(10.8 \times 10^{9} / \mathrm{L}\right.$ [8.3-18.1], $7.35 \times 10^{9} / \mathrm{L}[5.3-10.5], 10.7 \times 10^{9} / \mathrm{L}[7.7-16.8]$, respectively, $\mathrm{P}<0.0001$ ). The maximal IPF\% among the Covid-19 group was higher than the stable group and similar to the AMI group. The maximal IPC in Covid-19 was higher than the maximal IPC in both the stable and AMI groups (COVID-19: $14.4 \times 10^{9} / \mathrm{L}$ [9.4-20.9], AMI: $10.9 \times 10^{9} / \mathrm{L}$ [7.6-15.2], $\mathrm{P}=0.0035$, Stable: $7.55 \times 10^{9} / \mathrm{L}$ [5.55-10.5], $\left.\mathrm{P}<0.0001\right)$. Patients with Covid-19 have increased immature platelets indices compared to stable patients with cardiovascular risk factors, and as the disease progresses also compared to AMI patients. The enhanced platelet turnover and reactivity may have a role in the development of thrombotic events in Covid-19 patients.
\end{abstract}

Keywords Coronavirus disease $2019 \cdot$ SARS-CoV-2 infection $\cdot$ Thrombosis · Platelet aggregation inhibitors · Reticulated platelets · Immature platelets

\section{Abbreviations}

AMI

CAD

Covid-19

Acute myocardial infarction

Coronary artery disease

Coronavirus disease 2019

Amir Cohen and Emanuel Harari contributed equally to the study.

Eli I. Lev

eli1@assuta.co.il

1 Cardiology Department, Assuta Ashdod Medical Center, The Faculty of Health Sciences, Ben-Gurion University, 7 Harefua St, Ashdod, Israel

2 Laboratory Division, Assuta Ashdod Medical Center, The Faculty of Health Sciences, Ben-Gurion University, Ashdod, Israel

3 The School of Psychological Sciences, Tel-Aviv University, Tel-Aviv, Israel

4 Intensive Care Department, Assuta Ashdod Medical Center, The Faculty of Health Sciences, Ben-Gurion University, Ashdod, Israel
IPC Immature platelet count

IPF Immature platelet fraction

PT Prothrombin time

RT-PCR Reverse transcription polymerase chain reaction

SARS-CoV-2 Severe acute respiratory syndrome coronavirus 2

VTE Venous thromboembolism

\section{Background}

Coronavirus disease 2019 (Covid-19) is a pandemic with global effect on morbidity and mortality. The clinical characteristics of the disease have been reported in several case series, and can range from mild respiratory infection to multi organ dysfunction syndrome and fatal respiratory failure [1-4]. Severe Covid-19 is associated with a high incidence of venous thromboembolic events (VTE) [5]. In a cohort of 3 hospitals 
from the Netherlands, describing 183 critically-ill Covid-19 patients, receiving prophylactic anticoagulation, the cumulative incidence of both venous and arterial thrombotic complications (acute pulmonary embolism, deep-vein thrombosis, ischemic stroke, myocardial infarction or systemic arterial embolism), was 31\%, mainly consisting of VTE [6]. Recently, several published case series reported arterial thrombotic events consisting of acute ST-elevation myocardial infarction and acute stroke among patients with Covid-19 [7-9]. Covid-19 is accompanied by several hematologic abnormalities, among them thrombocytopenia, prolonged PT, elevated D-dimmer and fibrinogen degradation products, as well as microangiopathy $[10,11]$. Some of the hematological abnormalities, such as increased D-dimer levels, were shown to be associated with short-term mortality $[12,13]$. The association of thrombocytopenia on one hand and increased thrombotic risk, including arterial thrombotic events, on the other, raises the possibility of platelet hyper-reactivity, as a contributing factor in some patients with Covid-19. Identifying Covid-19 patients with increased risk for thrombotic events may have therapeutic implications for the recommended antithrombotic regimen.

Reticulated platelets (RPs) are young immature platelets recently released to the circulation from the bone marrow by megakaryocytes. They have a high dense granules content and residual mRNA. They are believed to be more pro-thrombotic and hyper-reactive than mature platelets [14-16]. They are known to be associated with thrombotic propensity and have a greater predilection for thrombus formation. Increased levels of RPs have been associated with high platelet turnover, and with arterial thrombotic events including acute coronary syndrome and acute stroke [14-16]. An automated assay-immature platelet fraction (IPF), correlates directly with reticulated platelets level, evaluated by the more complex method of flow cytometry [17]. In patients with coronary artery disease (CAD) and acute myocardial infarction (AMI), IPF is an independent predictor for major adverse cardiovascular events, including cardiovascular death $[18,19]$. Furthermore, IPF and IPFrelated indices are strong independent predictors of response to antiplatelet treatment among patients with CAD [20].

The aim of the current study was to assess immature platelets by measuring IPF levels and other IPF-related indices in patients with Covid-19, compared to patients with acute myocardial infarction (AMI) and stable patients with cardiovascular risk factors.

\section{Methods}

\section{Study design and participants}

This was a prospective cohort study which compared consecutive patients with Covid-19 (study group) to 2 control groups from ongoing studies. The study group included consecutive patients admitted to the Assuta Ashdod Medical Center in Israel with confirmed novel corona virus (SARSCoV-2) infection and Covid-19 from March 30, 2020 to April 28, 2020. There were no exclusion criteria for this group except for patient refusal to participate in the study. Diagnosis of Covid-19 was made by at least one positive real time RT-PCR assay with respiratory symptoms and radiological findings. Disease severity was defined according to the Modified Early Warning Score (MEWS) as well as degree of respiratory support [21]. Blood samples for the Covid-19 group were drawn on admission, 3 days afterwards and again, post one week of hospitalization. For patients with severe disease an additional blood test was drawn after the first week of hospitalization. The second group included patients, hospitalized at the Assuta Ashdod Medical Center, Israel, with acute myocardial infarction (AMI). They had either ST-segment elevation MI or non ST-segment elevation MI, and all patients underwent percutaneous coronary intervention (PCI). Blood samples for this group were drawn at 4 time points: (a) on admission to the hospital before receiving P2Y12 inhibitors; (b) 1 day post-PCI; (c) 3-4 days after PCI; (d) 30 days post-PCI. Exclusion criteria to this group were anemia (hemoglobin $<10 \mathrm{~g} / \mathrm{dL}$ ), thrombocytopenia (platelet $<100 \times 10^{9} / \mathrm{L}$ ), and chronic hemato-oncologic disease. The third group included patients with cardiovascular risk factors (diabetes, hypertension, and/or hyperlipidemia,) and/or stable chronic CAD, followed at the Cardiology clinics at the Assuta Ashdod Medical Center, Israel. Blood samples for this group were drawn at two time points, one month apart. Exclusion criteria to this group were also anemia (hemoglobin $<10 \mathrm{~g} / \mathrm{dL}$ ), thrombocytopenia (platelet count $<100$ $\times 10^{9} / \mathrm{L}$ ), and chronic hemato-oncologic disease. Patients in the second group (AMI cohort) and the third group (stable cohort) were recruited prospectively in the period of January 2019-March 2020.

Blood samples were evaluated for immature platelet fraction (IPF) using an automated analyzer (Sysmex XN-3000, Sysmex America Inc. Mundelein, Illinois), which uses fluorescent dyes containing oxazine and ethylene glycol. This system discriminates between mature and immature platelets and reports the immature platelet fraction as percentage. IPC (immature platelet count)—was calculated by multiplying IPF and total platelet count, representing the absolute count of immature platelets $\left(\times 10^{9} / \mathrm{L}\right)$. All groups' results for IPF and IPC, are presented as baseline value and maximal value (from all blood tests taken).

\section{Statistical analysis}

Categorical variables were described as frequency rates and percentages, and continuous variables were described using median, and interquartile range (IQR) values. Continuous 
variables were compared using independent group t tests when the data were normally distributed; otherwise, the Mann-Whitney test was used. All statistical analyses were performed using JMP software version 15.1.0 - SAS Institute Inc, NC USA. For comparisons, a 2 -sided $\alpha$ of less than 0.05 was considered statistically significant.

\section{Results}

The study included 47 consecutive patients with confirmed Covid-19 (the study group), 100 patients with AMI (AMI control group) and 64 patients with cardiovascular risk factors and/or stable CAD (Stable control group). The median age of the Covid-19 group was 56 years (IQR, 31-66; range, 17-90 years), and 28 (59.6\%) were men. Cardiovascular comorbidities and risk factors were present in more than half of the cohort $(63.8 \%)$, as described in Table 1. In the AMI control group, the median age was 59 years (IQR, 51-68), 82
$(82 \%)$ of the patients were men and $27(27 \%)$ had diabetes. Among the AMI group 54 patients (54\%) were hospitalized with ST-segment elevation MI and 46 (46\%) with non ST-segment elevation MI. In the stable control group, the median age was 68 years $(58-73), 41(64.1 \%)$ were men and $19(29.7 \%)$ had diabetes (Table 1$)$.

The IPF percentage on admission was higher in the Covid-19 group compared to the stable group (4.8\% [IQR 3.4-6.9] in the COVID group vs 3.5\% [IQR 2.7-5.1] in the stable cohort, $\mathrm{P}=0.0053)$. Similar level of $\mathrm{IPF} \%$ was observed among the Covid-19 and AMI groups $(4.55 \%$ [IQR 3.0-6.75] in the AMI cohort). IPC on admission was also higher in the COVID-19 group than the stable group $\left(10.8 \times 10^{9} / \mathrm{L}\right.$ [IQR $\left.8.3-18.1\right]$ in the COVID group versus $7.35 \times 10^{9} / \mathrm{L}[5.3-10.5]$ in the stable cohort, $\left.\mathrm{p}<0.0001\right)$, and similar among the COVID-19 and AMI groups $(10.7 \times$ $10^{9} / \mathrm{L}$ [IQR 7.7-16.8] in the AMI cohort), as described in Table 2 and Fig. 1. As with the baseline values, the maximal IPF percentage among the Covid-19 group was similar to
Table 1 Demographic, clinical and laboratory findings of patients on admission

\begin{tabular}{|c|c|c|c|c|}
\hline & $\begin{array}{l}\text { Covid-19 cohort } \\
\mathrm{n}=47\end{array}$ & $\begin{array}{l}\text { AMI cohort } \\
\mathrm{n}=100\end{array}$ & $\begin{array}{l}\text { Stable cohort } \\
n=64\end{array}$ & $\begin{array}{l}\mathrm{p} \text { value } \\
\text { Covid-19 vs. AMI, } \\
\text { Covid-19 vs. stable }\end{array}$ \\
\hline \multicolumn{5}{|c|}{ Demographics and clinical characteristics } \\
\hline $\begin{array}{l}\text { Age, median, (IQR), year } \\
\text { Sex, } n(\%)\end{array}$ & $56(31-66)$ & $59(51-68)$ & $68(58-73)$ & $0.0844,0.0003$ \\
\hline Male & $28(59.6)$ & $82(82.0)$ & $41(64.1)$ & $0.003,0.5$ \\
\hline Female & $19(40.4)$ & $18(18.0)$ & $23(35.9)$ & \\
\hline Weight (Kg) & $80.0(64.0-87.5)$ & $83.0(74.0-93.0)$ & $80.0(68.0-93.0)$ & $0.1340,0.4847$ \\
\hline Current smoker & $3(6.3)$ & $43(43)$ & $8(12.5)$ & $0.0001,0.29$ \\
\hline \multicolumn{5}{|l|}{ Comorbidities } \\
\hline Diabetes & $14(29.8)$ & $27(27)$ & $19(29.7)$ & $0.7,0.99$ \\
\hline Hypertension & $18(38.3)$ & $50(50)$ & $45(70.3)$ & $0.2,0.0008$ \\
\hline Dyslipidemia & $13(27.7)$ & $82(82)$ & $38(59.4)$ & $<0.00001,0.001$ \\
\hline Prior CAD & $8(17)$ & $35(35)$ & $13(20.3)$ & $0.03,0.7$ \\
\hline $\mathrm{CHF}$ & $1(2.1)$ & $14(14)$ & $10(15.6)$ & $0.03,0.02$ \\
\hline CKD & $5(10.5)$ & $9(9)$ & $5(7.8)$ & $0.75,0.6$ \\
\hline CABG & $1(2.1)$ & $2(2)$ & $1(1.6)$ & $0.96,0.82$ \\
\hline \multicolumn{5}{|c|}{ Laboratory findings (admission) } \\
\hline Hemoglobin (mg/dl) & $13.1(12.0-14.6)$ & $14.25(13.0-15.4)$ & $13(12.1-13.8)$ & $0.0032,0.3776$ \\
\hline White blood cells $\times 10^{9} / \mathrm{L}$ & $7.10(5.30-8.95)$ & $10.4(8.4-13.1)$ & $6.65(5.53-8.45)$ & $<0.0001,0.7425$ \\
\hline Lymphocytes $\times 10^{9} / \mathrm{L}$ & $1.25(0.80-1.80)$ & $2.2(1.50-2.88)$ & $1.70(1.33-2.20)$ & $<0.0001,0.0002$ \\
\hline Platelets $\times 10^{9} / \mathrm{L}$ & $210(192-316)$ & $230(202-268)$ & $211(172-235)$ & $0.5601,0.0838$ \\
\hline Creatinine (mg/dL) & $0.80(0.60-1.00)$ & $0.90(0.80-1.10)$ & $0.90(0.70-1.10)$ & $0.0112,0.0600$ \\
\hline CRP (mg/L) & $18.5(3.3-75.0)$ & $4.7(2.0-10.5)$ & $2.30(1.0-5.0)$ & $0.0007,<0.0001$ \\
\hline \multicolumn{5}{|l|}{ Medications, n (\%) } \\
\hline Aspirin & $16(34)$ & $93(93)$ & $15(23.4)$ & $<0.0001,0.22$ \\
\hline P2Y12 inhibitors & $3(6.4)$ & $99(99)$ & $4(6.3)$ & $<0.0001,0.52$ \\
\hline ACEI/ARB & $17(36.2)$ & $78(75)$ & $37(57.8)$ & $<0.0001,0.025$ \\
\hline Beta blockers & $12(25.5)$ & $80(80)$ & $39(60.9)$ & $<0.0001,0.0002$ \\
\hline Statins & $13(27.6)$ & $99(99)$ & $31(48.4)$ & $<0.0001,0.028$ \\
\hline Anti-diabetes drugs & $14(29.8)$ & $25(25)$ & $10(15.6)$ & $0.54,0.07$ \\
\hline
\end{tabular}


Table 2 Immature platelets indices in the Covid-19, AMI and stable Cohorts

\begin{tabular}{llllll}
\hline & $\begin{array}{l}\text { Covid-19 cohort } \\
\mathrm{n}=47\end{array}$ & $\begin{array}{l}\text { AMI cohort } \\
\mathrm{n}=100\end{array}$ & $\begin{array}{l}\text { Stable cohort } \\
\mathrm{n}=64\end{array}$ & $\begin{array}{l}\mathrm{p} \text { value } \\
\text { Covid-19 vs. AMI }\end{array}$ & $\begin{array}{l}\mathrm{p} \text { value } \\
\text { Covid-19 vs. Stable }\end{array}$ \\
\hline $\begin{array}{l}\text { IPF }(\%) \\
\text { Admission }\end{array}$ & $4.80(3.40-6.90)$ & $4.55(3.03-6.75)$ & $3.50(2.70-5.08)$ & 0.3255 & 0.0053 \\
$\begin{array}{l}\text { Maximal } \\
\text { IPC } \times\left(10^{9} / \mathrm{L}\right)\end{array}$ & $5.60(3.70-6.90)$ & $5.20(3.40-7.50)$ & $3.80(2.80-5.38)$ & 0.6979 & 0.0004 \\
$\begin{array}{l}\text { Admission } \\
\text { Maximal }\end{array}$ & $10.8(8.30-18.1)$ & $10.7(7.73-16.8)$ & $7.35(5.3-10.50)$ & 0.4307 & $<0.0001$ \\
\hline
\end{tabular}

$\mathrm{p}$ values were calculated using Mann-Whitney test

that of the AMI group, but higher than that of the stable group (Table 2, Fig. 1). However, the maximal IPC in the Covid-19 group was significantly higher, compared to both control groups $\left(14.4 \times 10^{9} / \mathrm{L}\right.$ [9.38-20.9] in the Covid-19 group vs $10.9 \times 10^{9} / \mathrm{L}$ [7.6-15.2] in the AMI group, $\mathrm{p}=$ 0.0035 , and $7.55 \times 10^{9} / \mathrm{L}[5.55-10.5]$ in the stable group, $\mathrm{P}<0.0001)$.

Among the Covid-19 cohort, 44 patients had mild to moderate disease, and 3 had severe disease on admission. During their hospital course, 13 of the patients admitted with mild-moderate disease developed severe disease, including one patient who developed massive pulmonary emboli and one patient who died. Immature platelets indices (IPF and IPC) were not associated with the severity of Covid-19 as defined by the MEW Score, neither on admission, nor during the subsequent hospital course (Table 3; Fig. 2).

\section{Discussion}

To our knowledge, the current study is the first to examine indices of platelet turnover and reactivity-IPF and IPC, in patients with Covid-19 respiratory disease. The main findings of the study are that patients with Covid-19 had higher baseline (admission) levels of IPF and IPC than stable patients with cardiovascular risk factors, and their maximal IPC levels were higher than the maximal IPC of both patients with AMI (known to have hyper-reactive platelets and enhanced platelet turnover), and patients with cardiovascular risk factors. These findings imply that immature platelets may have a role in the development of thrombotic events in Covid-19 patients, especially the recently reported acute arterial events, which are primarily platelet- mediated [7-9].

The main mechanism for the high levels of immature platelets in patients with Covid-19, as reflected by the high values of IPF and IPC, is most likely increased platelet turnover. Acute illnesses are often associated with increased platelet turnover and enhanced thrombopoiesis, although this has mainly been demonstrated for conditions associated with acute thrombotic events such as AMI and stroke $[22,23]$. In certain viral infections, platelet specific receptors have been reported to interact with viral pathogens [24], potentially leading to a systemic inflammatory response, and increased platelet consumption and removal, with resultant enhanced thrombopoiesis [25-27]. It should be noted, however, that the lack of association between immature platelet indices and Covid-19 disease severity in our study, does not support a direct virus-platelet interaction, rather a systemic inflammatory response to the virus, with resultant enhanced thrombopoiesis.

We examined in the current study both IPF and IPC (\%IPF * total platelet count) as indices of platelet turnover and reactivity. We have found that the maximal values of IPC in patients with Covid-19 were higher than the maximal IPC values of both patients with AMI and stable patients with cardiovascular risk factors. Especially remarkable are the elevated values of IPC in Covid-19 patients compared to patients with AMI, known to have hyper-reactive platelets and enhanced platelet turnover [22]. It is important to note that IPC has been found to be the strongest independent platelet-derived predictor of antiplatelet response to thienopyridines (including 
Fig. 1 Immature platelets indices in the Covid-19, AMI and stable groups. Medians and 95\% CI
IPF on admission

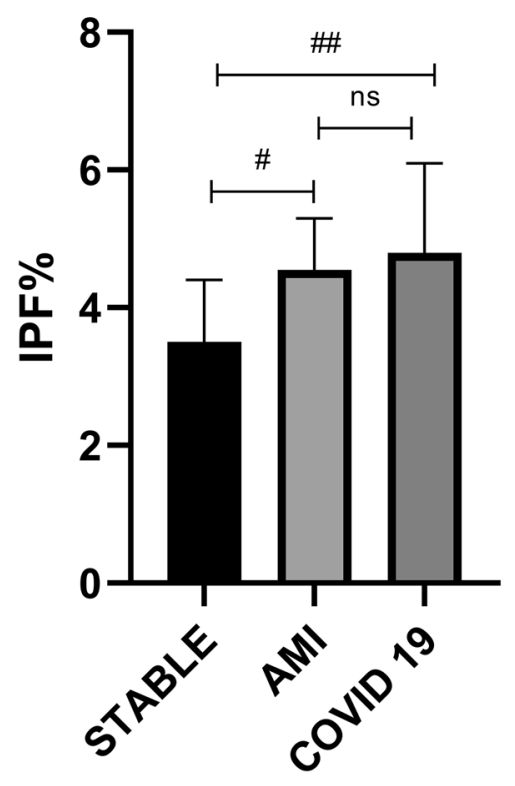

Maximal IPF

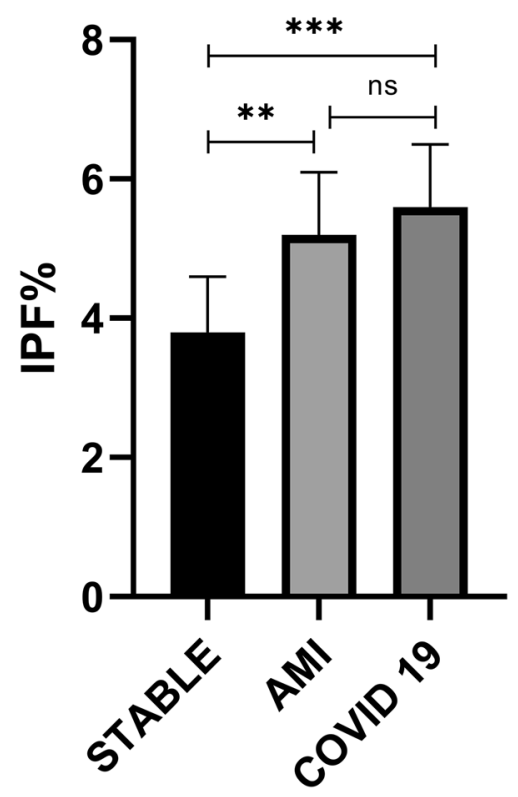

Mann-Whitney test

$$
\begin{aligned}
& { }^{*} P<0.0001 \\
& { }^{* *} P=0.0005
\end{aligned}
$$

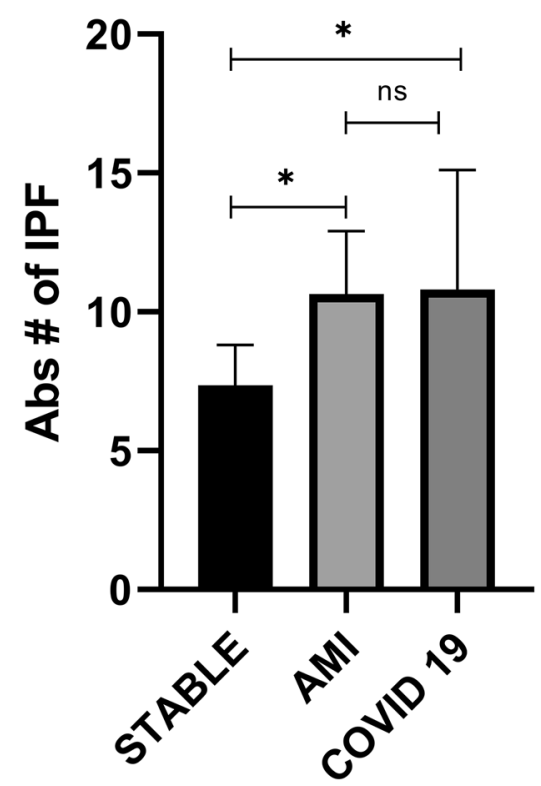

Maximal IPC

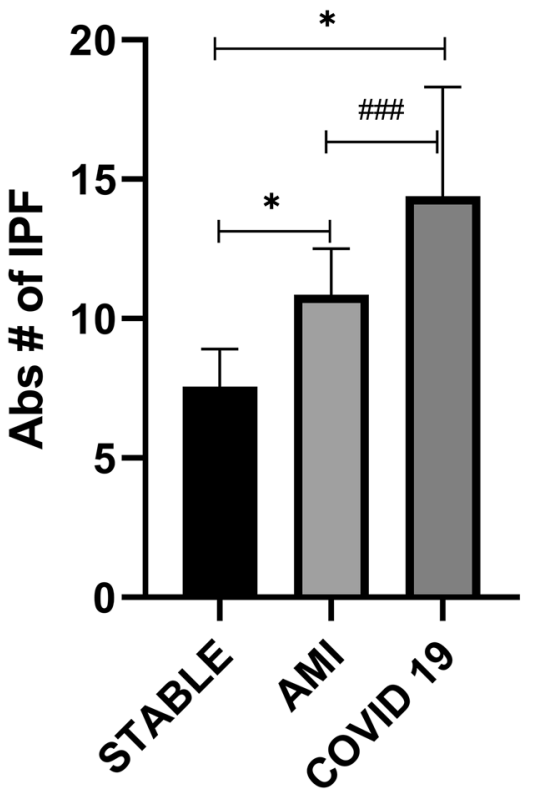

\# $P=0.0053$

\#\# $P=0.0008$

*** $\mathrm{P}=0.0004$

\#\#\# $P=0.0035$ 
Table 3 Immature platelets indices in according to Covid19 disease severity

\begin{tabular}{llll}
\hline & $\begin{array}{l}\text { Mild-Moderate Covid-19 } \\
(\mathrm{n}=31)\end{array}$ & $\begin{array}{l}\text { SEVERE Covid-19 } \\
(\mathrm{n}=16)\end{array}$ & $\mathrm{p}$ value \\
\hline $\begin{array}{l}\text { Mew Score (max) } \\
\text { Platelets (admission) }(\times\end{array}$ & $1(0-3)$ & $7(7-8)$ & 0.16 \\
$\quad 205(182-267)$ & $250(190-454)$ & \\
$\mathrm{IPF}(\%)$ & & 0.06 \\
Admission & $5.7(3.8-7.9)$ & $4.2(2.8-5.68)$ & 0.45 \\
Maximal & $5.6(3.80-7.33)$ & $5.6(3.1-6.6)$ & 0.64 \\
IPC count $\left(\times 10^{9} / \mathrm{L}\right)$ & & $10.70(7.83-18.1)$ & 0.73 \\
Admission & $12.0(8.6-18.1)$ & $14.3(8.7-20.3)$ & \\
Maximal & $12.5(9.3-18.4)$ & & \\
\hline
\end{tabular}

$\mathrm{p}$ values were calculated using Mann-Whitney test parameters such as the CYP2C19*2 polymorphism, ADPinduced impedance aggregometry and various immature platelet indices) [20]. IPC has also been shown to be a strong independent predictor of major adverse cardiac events in patients with CAD [19]. Thus, the elevated IPC values found in Covid-19 patients might have important clinical significance. The increased IPF and IPC values at admission and during the hospital course suggest that immature platelet markers may be employed for risk stratification in Covid-19 patients. In addition, Covid-19 patients with elevated levels of IPC (above a certain threshold) may benefit from antiplatelet therapy.

The antithrombotic therapy regimen in patients with Covid-19 is challenging. The combination of thrombocytopenia and consumption coagulopathy, together with high risk for VTE and arterial thrombotic events makes the treatment of Covid-19 particularly complex [17]. Current protocols recommend that hospitalized patients with confirmed Covid-19 should be treated with VTE prophylaxis, unless there are specific contraindications [17]. Due to higher VTE risk in patients with severe disease, several protocols suggest they should be treated with full dose of anticoagulation. There are still unanswered questions about treatment duration and whether antiplatelet therapy should be administered as well. These challenges emphasized the need for better tools for thrombosis risk stratification and particularly platelet involvement.

Unexpectedly, we did not find an association between immature platelet indices and Covid-19 disease severity.
This is in contrast to the association of other thrombotic indices (such as D-dimer and fibrinogen degradation products) with disease severity [13]. It is possible that the relatively small size of the Covid-19 group $(n=47)$, and the limited number of patients with severe disease (3 patients on admission, and 13 during the subsequent hospital course), has limited the ability to detect differences in immature platelet indices according to disease severity.

The current study has several limitations. Although the 3 study groups were all prospectively enrolled and examined, they were recruited at different time periods (the 2 control groups were recruited during a roughly one-year period before and up to the Covid-19 outbreak). Furthermore, the two control groups had several exclusion criteria, while no such criteria, were applied for the Covid-19 group. Nevertheless, the 3 groups were relatively wellmatched in terms of cardiac risk factors and the proportion of patients with CAD. In addition, despite the different time periods the laboratory assays employed for IPF were identical for all patients.

To conclude, patients with Covid-19 respiratory disease appear to have enhanced platelet turnover and reactivity, as evidenced by increased levels of immature platelet indices (especially IPC), compared to both control groups. Further research is required to explore the mechanisms of this phenomenon, and to examine the clinical impact of elevated immature platelet indices on the risk of thromboembolic events, in patients with Covid-19. 
Fig. 2 Immature platelets indices in according to Covid19 maximal disease severity. Medians and $95 \% \mathrm{CI}$
Admission IPF vs. COVID-19 Severity

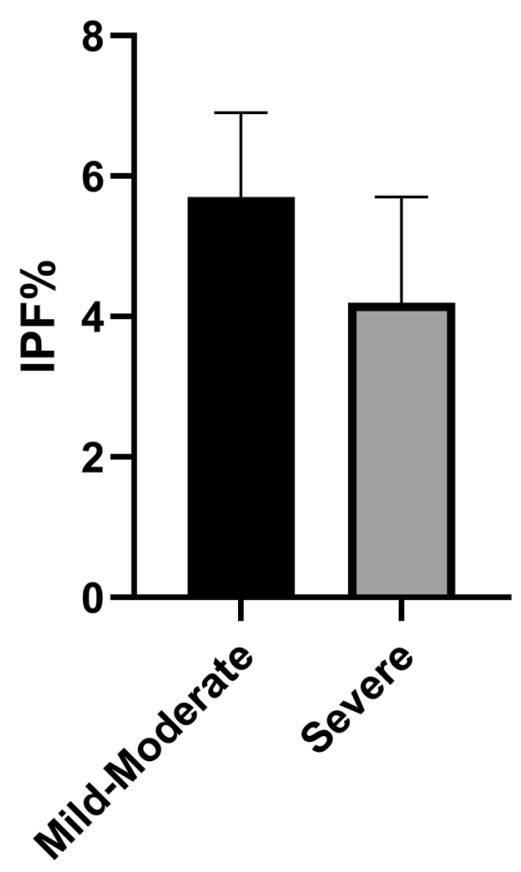

Maximal IPF vs. COVID-19 Severity

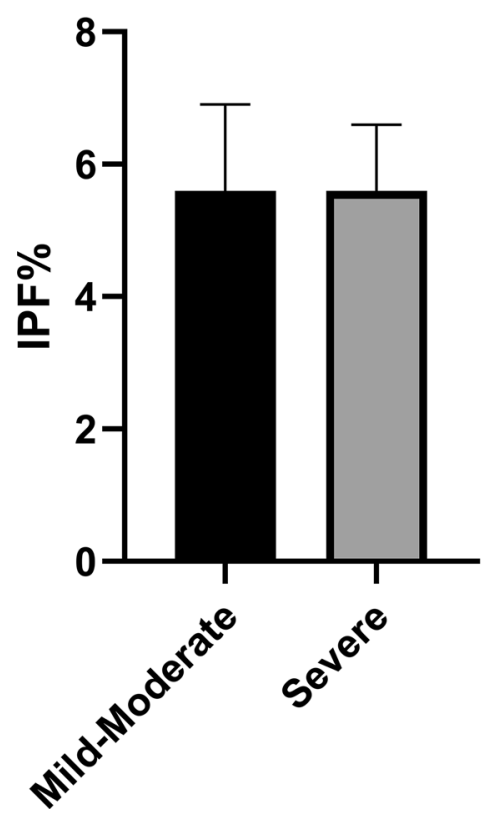

Admission IPC vs. COVID-19 Severity

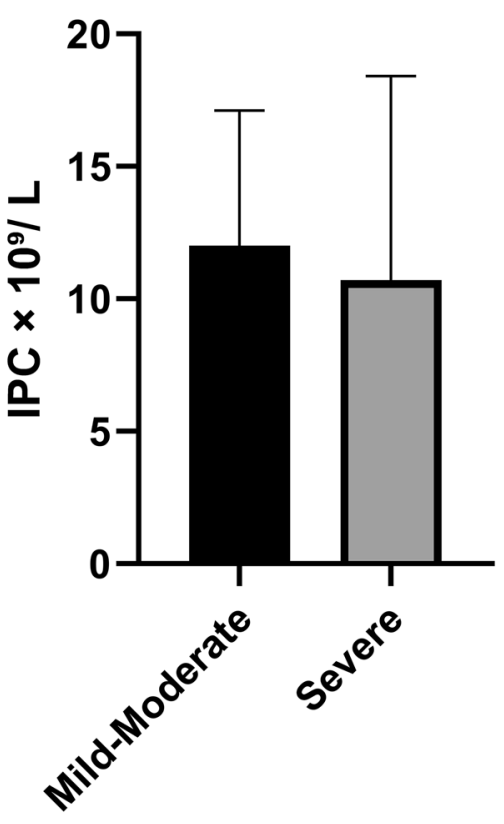

Maximal IPC vs. COVID-19 Severity

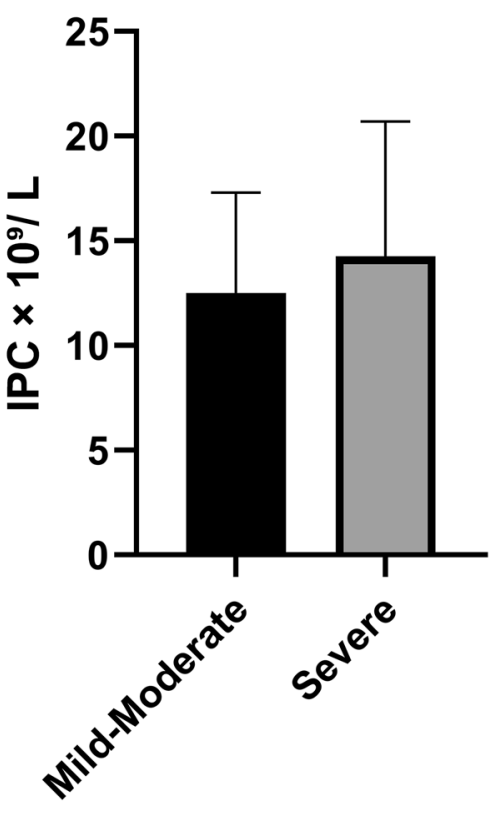


Author contributions $\mathrm{AC}$ and $\mathrm{EH}$ analyzed the results and wrote the paper. MC and GB performed all laboratory measurements. AC, NKL and TM collected the clinical data. AL-F and EY collected the control group data. EH and YS performed the statistical analysis. AM and EL designed the research and revised the manuscript.

Funding The funding of this study was based on internal resource only.

\section{Compliance with ethical standards}

Conflict of interest The authors of this paper declare no conflicts or competing interests.

Ethics approval The study was approved by the investigational review board (ethics committee) of the Assuta Ashdod Medical Center, Israel.

Informed consent All subjects (in all 3 groups) provided written informed consent. The authors vouch for the accuracy and completeness of the data and agreed to this publication.

\section{References}

1. Chen N, Zhou M, Dong X, Qu J, Gong F, Han Y et al (2020) Epidemiological and clinical characteristics of 99 cases of 2019 novel coronavirus pneumonia in Wuhan, China: a descriptive study. Lancet 395(10223):507-513. https://doi.org/10.1016/ S0140-6736(20)30211-7

2. Huang C, Wang Y, Li X, Ren L, Zhao J, Hu Y et al (2020) Clinical features of patients infected with 2019 novel coronavirus in Wuhan. China Lancet 395(10223):497-506. https://doi. org/10.1016/S0140-6736(20)30183-5

3. Wang D, Hu B, Hu C, Zhu F, Liu X, Zhang J et al (2020) Clinical characteristics of 138 hospitalized patients with 2019 novel coronavirus-infected pneumonia in Wuhan, China. JAMA. https ://doi.org/10.1001/jama.2020.1585

4. Mehra MR, Desai SS, Kuy S, Henry TD, Patel AN (2020) Cardiovascular disease, drug therapy, and mortality in Covid-19. N Engl J Med. https://doi.org/10.1056/NEJMoa2007621

5. Cui S, Chen S, Li X, Liu S, Wang F (2020) Prevalence of venous thromboembolism in patients with severe novel coronavirus pneumonia. J Thromb Haemost. https://doi.org/10.1111/jth.14830

6. Klok FA, Kruip M, van der Meer NJM, Arbous MS, Gommers $\mathrm{D}$, Kant KM et al (2020) Incidence of thrombotic complications in critically ill ICU patients with COVID-19. Thromb Res. https ://doi.org/10.1016/j.thromres.2020.04.013

7. Bangalore S, Sharma A, Slotwiner A, Yatskar L, Harari R, Shah B et al (2020) ST-segment elevation in patients with Covid-19-a case series. N Engl J Med. https://doi.org/10.1056/NEJMc20090 20

8. Oxley TJ, Mocco J, Majidi S, Kellner CP, Shoirah H, Singh IP et al (2020) Large-vessel stroke as a presenting feature of Covid19 in the young. N Engl J Med. https://doi.org/10.1056/NEJMc 2009787

9. Stefanini GG, Montorfano M, Trabattoni D, Andreini D, Ferrante G, Ancona M et al (2020) ST-elevation myocardial infarction in patients with COVID-19: clinical and angiographic outcomes. Circulation. https://doi.org/10.1161/CIRCULATIONAHA.120.04752 5

10. Chan JF, Yuan S, Kok KH, To KK, Chu H, Yang J et al (2020) A familial cluster of pneumonia associated with the 2019 novel coronavirus indicating person-to-person transmission: a study of a family cluster. Lancet 395(10223):514-523. https://doi. org/10.1016/S0140-6736(20)30154-9

11. Lippi G, Plebani M, Henry BM (2020) Thrombocytopenia is associated with severe coronavirus disease 2019 (COVID-19) infections: a meta-analysis. Clin Chim Acta 506:145-148. https://doi. org/10.1016/j.cca.2020.03.022

12. Zhou F, Yu T, Du R, Fan G, Liu Y, Liu Z et al (2020) Clinical course and risk factors for mortality of adult inpatients with COVID-19 in Wuhan, China: a retrospective cohort study. Lancet 395(10229):1054-1062. https://doi.org/10.1016/S0140 $-6736(20) 30566-3$

13. Tang N, Li D, Wang X, Sun Z (2020) Abnormal coagulation parameters are associated with poor prognosis in patients with novel coronavirus pneumonia. J Thromb Haemost 18(4):844-847. https://doi.org/10.1111/jth.14768

14. Bernlochner I, Goedel A, Plischke C, Schupke S, Haller B, Schulz $\mathrm{C}$ et al (2015) Impact of immature platelets on platelet response to ticagrelor and prasugrel in patients with acute coronary syndrome. Eur Heart J 36(45):3202-3210. https://doi.org/10.1093/eurheartj/ ehv326

15. Freynhofer MK, Gruber SC, Grove EL, Weiss TW, Wojta J, Huber K (2015) Antiplatelet drugs in patients with enhanced platelet turnover: biomarkers versus platelet function testing. Thromb Haemost 114(3):459-468. https://doi.org/10.1160/TH15-02-0179

16. Lev EI (2016) Immature platelets: clinical relevance and research perspectives. Circulation 134(14):987-988. https://doi. org/10.1161/CIRCULATIONAHA.116.022538

17. Pons I, Monteagudo M, Lucchetti G, Munoz L, Perea G, Colomina I et al (2010) Correlation between immature platelet fraction and reticulated platelets. Usefulness in the etiology diagnosis of thrombocytopenia. Eur J Haematol. 85(2):158-163. https://doi. org/10.1111/j.1600-0609.2010.01468.x

18. Cesari F, Marcucci R, Gori AM, Caporale R, Fanelli A, Casola $\mathrm{G}$ et al (2013) Reticulated platelets predict cardiovascular death in acute coronary syndrome patients Insights from the AMIFlorence 2 Study. Thromb Haemost. 109(5):846-853. https://doi. org/10.1160/TH12-09-0709

19. Ibrahim H, Schutt RC, Hannawi B, DeLao T, Barker CM, Kleiman NS (2014) Association of immature platelets with adverse cardiovascular outcomes. J Am Coll Cardiol 64(20):2122-2129. https://doi.org/10.1016/j.jacc.2014.06.1210

20. Stratz C, Bomicke T, Younas I, Kittel A, Amann M, Valina CM et al (2016) Comparison of immature platelet count to established predictors of platelet reactivity during thienopyridine therapy. J Am Coll Cardiol 68(3):286-293. https://doi.org/10.1016/j. jacc.2016.04.056

21. Subbe CP, Kruger M, Rutherford P, Gemmel L (2001) Validation of a modified early warning score in medical admissions. QJM 94(10):521-526. https://doi.org/10.1093/qjmed/94.10.521

22. Lakkis N, Dokainish H, Abuzahra M, Tsyboulev V, Jorgensen J, De Leon AP et al (2004) Reticulated platelets in acute coronary syndrome: a marker of platelet activity. J Am Coll Cardiol 44(10):2091-2093. https://doi.org/10.1016/j.jacc.2004.05.033

23. McCabe DJ, Harrison P, Sidhu PS, Brown MM, Machin SJ (2004) Circulating reticulated platelets in the early and late phases after ischaemic stroke and transient ischaemic attack. Br J Haematol 126(6):861-869. https://doi.org/10.1111/j.1365-2141.2004.05137 .x

24. Seyoum M, Enawgaw B, Melku M (2018) Human blood platelets and viruses: defense mechanism and role in the removal of viral pathogens. Thromb J 16:16. https://doi.org/10.1186/s1295 9-018-0170-8

25. Assinger A (2014) Platelets and infection-an emerging role of platelets in viral infection. Front Immunol 5:649. https://doi. org/10.3389/fimmu.2014.00649 
26. Hottz ED, Bozza FA, Bozza PT (2018) Platelets in immune response to virus and immunopathology of viral infections. Front Med (Lausanne) 5:121. https://doi.org/10.3389/fmed.2018.00121

27. Connolly-Andersen AM, Sundberg E, Ahlm C, Hultdin J, Baudin M, Larsson J et al (2015) Increased thrombopoiesis and platelet activation in hantavirus-infected patients. J Infect Dis 212(7):1061-1069. https://doi.org/10.1093/infdis/jiv161
Publisher's Note Springer Nature remains neutral with regard to jurisdictional claims in published maps and institutional affiliations. 